\title{
Comparative Study of Methods of Risks Assessment in Rural Power Network
}

\author{
Xiaoqiang Song ${ }^{1}$ and Tao Yang ${ }^{2, *}$ \\ ${ }^{1}$ College of Information and Electrical Engineering, \\ Shenyang Agriculture University, Shenyang 110866, China \\ ${ }^{2}$ College of Information and Electrical Engineering, \\ Shenyang Agriculture University, Shenyang 110866, China \\ songxiaoqiang323@163.com, yangtaosx@yahoo.com.cn
}

\begin{abstract}
The key to security risks assessment in rural power network is hazards assessment, it is very important to select a proper assessment methods. Based on comparative study of characteristic, applicable condition and application scope of operating conditions hazard assessment method(LEC), risk assessment code method(RAC), Fault type and effect analysis (FMEA), Event Tree Analysis(ETA) and etc, the paper propose that LEC and RAC are appropriate methods for security risks assessment of rural power network, the example shows its applicability and effectiveness. The conclusions offer a reference for security risks of rural power network.
\end{abstract}

Keywords: Rural power network, Security risks assessment, LEC, RA.

\section{Introduction}

According to power enterprises own characteristics, it should establish and implement a standardized, scientific, and Systematic safety management system, to make the reasonable choice of hazard and risk assessment methods, execute the risk identification and risk assessment systematically, develop practical and reliable risks control measures to enhance safety management level and the scientificity of security precautions.

In the actual operation process, each risk assessment method of hazard exist certain flaws. For instance, fault Model and Impact Analysis(FMFA) only commonly involves in the risk failure analysis, wasting time and without considering the comprehensive factors during the actual operation; Event Tree Analysis (ETA) cannot analysis parallel results, therefore the analysis results are not detailed enough; Fault Tree Analysis(FTA) constitutes the large tree, which is not easy to understand and is different to the flowchart of the system, so it's difficult to convert, meanwhile there is not a single answer in mathematics, and its logical relationship is complex, it isn't applicable to grass-roots workers. Facing the actual situation of the power system in China, namely lack of the actual data about failure rate of the power equipment and error probability result from people, it's difficult to quantitatively analyze. The operating conditions hazard assessment method (LEC) is

* Corresponding author. 
appropriate for the risk assessment of personal injury, and the quantitative evaluation of the size of the risk, through the multiplication of the three factors associated with system risk, of which L (the possibility of accident happening), E (the frequency degree of exposure to the dangerous environment) and $\mathrm{C}$ (the consequences caused by an accident). risk assessment code method(RAC) is applicable to all kinds of damage and loss evaluation (including property and equipment), which considers the two factors: the possibility of an accident to happen and the consequences caused by an accident. Therefore in the power system, due to complexity of systems, many of equipments, the poor environment and other characteristics, LEC and RAC are often used for the risk assessment of hazard.

\section{Operation Conditions Hazard Assessment Method (LEC)}

\subsection{Brief Introduction of LEC Method}

Operation conditions hazard assessment method, also known as LEC, the model is:

$$
D=L * E * C
$$

The size of the $D$ value at risk depends on $L$, the possibility of accident happening, $E$, namely the frequency of exposure to dangerous environment and $C$, the possible consequences once the accident happened. This assessment method is simple to operate, and another characteristic is that its division of danger level is clear. But because it is mainly based on experience to determine the score of LEC, there exist certain limitations. It is a kind of semi-quantitative evaluation method. Therefore in the risk assessment it is required that the personnel who participate in the risk assessment should have the certain experience and make evaluation objectively and fairly.

\subsection{The LEC Score and Description}

$L$ is the score and description about the possibility of accident happening, $E$ is the score and description about the frequency of exposure to dangerous environment, $C$ is the score and description about the consequences caused by an accident. The score $D$ can be obtained by formula (1). Which state the risk of operation is on can be evaluated, so corresponding measures can be taken.

The purpose of this kind of treatment is to face a certain concrete hazard, according to the risk levels of it, and security levels are limited after preventing and controlling. Such as extremely dangerous hazard, although the preventing and controlling measures are perfect, the risk level is also huge even in the best condition; for a dangerous or general dangerous hazard even without prevention and control measures, the most terrible conclusion is risky and can not upgrade a higher risk level upgrade, which is truthfulness.

\section{Risk Assessment Exponent Matrix Method (RAC)}

Severity shall be divided into seven levels, and the possibility of pernicious events shall be divided into five levels. (Table 1 showed below). Severity of the pernicious events 
act as column items of the table, the possibility of pernicious events record as row items of the table, such a two-dimensional form is made into, and qualitative Taiex is given on the intersection of the rows and columns, all the Taiex form a matrix, which is called RAC. It is a kind of qualitative evaluation method.

By the LEC method, the possibility of accident happening and the frequency of exposure to dangerous environment are related, when exposures frequently occur, the possibility of accident will increase, so we can form a level table about the possibility of pernicious events through the relationship between them (as table 1).

Table 1. Possibility Levels of harmful events

\begin{tabular}{ll}
\hline Score & \multicolumn{1}{c}{ Description } \\
\hline $\mathrm{A}$ & When frequent exposure to dangerous environment, danger is \\
$\mathrm{B}$ & quite likely to happen \\
$\mathrm{C}$ & Expose to working time everyday, danger is probable \\
$\mathrm{D}$ & Once a week,or expose by chance, Possible, but not often \\
$\mathrm{E}$ & Expose once a month,Possibility is small, absolutely accident \\
\hline
\end{tabular}

Table 2. Levels of the Severity

\begin{tabular}{ccc}
\hline $\begin{array}{l}\text { Levels of } \\
\text { the Severity }\end{array}$ & $\begin{array}{l}\text { Explanation } \\
\text { of levels }\end{array}$ & Description \\
\hline I & Catastrophe & Many people die \\
II & Disaster & Many died \\
III & Very serious & One died \\
IV & Serious & Serious injury \\
V & major & Cripple \\
VI & Mild & $\begin{array}{c}\text { Compelling and need for } \\
\text { ambulance } \\
\end{array}$ \\
VII & Slight & $\begin{array}{c}\text { Personnel injuries and } \\
\text { system damage is } \\
\text { lighter }\end{array}$ \\
\hline
\end{tabular}

Table 3. Risk assessment exponent

\begin{tabular}{cccccccc}
\hline $\begin{array}{c}\text { Levels of the } \\
\text { Severity }\end{array}$ & I & II & III & IV & V & VI & VII \\
\hline A & 1 & 2 & 3 & 4 & 5 & 7 & 13 \\
B & 2 & 5 & 6 & 7 & 8 & 9 & 16 \\
C & 4 & 6 & 8 & 9 & 10 & 11 & 18 \\
D & 8 & 10 & 11 & 12 & 13 & 14 & 19 \\
E & 12 & 5 & 12 & 13 & 15 & 17 & 20 \\
\hline
\end{tabular}


The elements in matrix are Taiex, also called the Risk assessment exponent. Corresponding risk assessment exponent matrix is below:

$$
\left[\begin{array}{ccccccc}
1 & 2 & 3 & 4 & 5 & 7 & 13 \\
2 & 5 & 6 & 7 & 8 & 9 & 16 \\
4 & 6 & 8 & 9 & 10 & 11 & 18 \\
8 & 10 & 11 & 12 & 13 & 14 & 19 \\
12 & 5 & 10 & 12 & 17 & 17 & 20
\end{array}\right]
$$

Risk assessment exponent is determined by combining the possibility and severity of pernicious events, risk index, the highest risk index is usually intended to be 1 , corresponding pernicious events is that danger and catastrophe occur frequently; The lowest risk index is intended to be 20 , corresponding pernicious events occur almost impossibly and consequences are slight accidents. The division of number grades is arbitrary, but it is convenient to distinguish the risk levels. It is not convenient to risk assessment whether the division is too meticulous or too rough. So it is required to decide according to the concrete object.

The size of the index in matrix will be divided into categories by acceptable degree, forming risk acceptance criteria or judge criteria. Among them: the $1 \sim 5$ index for unacceptable risks is unable to bear for the organization; $6 \sim 9$ for unwanted need to be decided whether to accept by the organization; $10 \sim 17$ is conditional acceptance, which can be accepted after the judgments by the organization, $18 \sim 20$ can be accepted without judging, thus forming the qualitative risk level.

\section{Cases Comparative Analysis of the LEC Method and RAC Method}

Two kinds of methods are compared based on the transformer in transformer maintenance work for risk assessment of events. Operating risks: high risk of falling objects, causing staff smashed casualties, here refers to the equipment, tools, lifting. In addition, through the analysis of the actual operation, we can work out the real working hours of the staff. Following the work principles, the chances of dangerous situation will be reduced. However, once the accident happened, it may appear the danger of smashing workers and their death.

In general, using the method of LEC to evaluate the events, the occurring of such events will be reduced. So the frequency $E$ is $0.5, L$ is $1, C$ is 15 . All these are based on the formula (1) $0.5 * 1 * 15=7.5$. If the result is slightly less than 20 , it will be in danger. We should prevent the danger happening, making it become an appropriate figure.

Using exponential matrix method can also evaluate such events. Comparing the harmfulness evaluates events in the table; we can see if the level is in the correct implementation rules, such events can be avoided. Thus, we should choose Grade E in the table. Comparing the Severity rating table, we know that once the high sinkers events 
are very serious, therefore Grade III is our choice. As the element in matrix is Taiex, we can get 12 , belonging to the risk of conditional acceptance risk, which is needed to confirmed by the organization.

According to the two methods, we learn that the two methods are similar in the following aspects: both of them need to choose corresponding level or grade based on the specific situations; both of them need to give real value by the operators according to the facts. To some extent, exponential matrix method is deformation of LEC. It combines $L$ value with $E$ value to form the grade table of the dangerous events, making the grade $C$ corresponds to the table Levels of the Severity. Exponential matrix method is more intuitive. It can directly read the evaluation index from the matrix form. Which kind of methods will be applied depends on actual operation assignments in the process of concrete operational practice.

\section{Conclusion}

There are many assessment methods of Hazard risk, but we should choose which kind of evaluation method based on the nature of the object, the complexity of the hazard and the ability of the personnel engaged in the hazard. For the basic operation personnel, they should choose relatively simple methods, such as LEC. For the technical and managerial personnel and risk assessment team members, they should choose relatively complex evaluation methods such as RAC method. Only using a variety of methods comparing the application of the same operation to get the comprehensive safety evaluation result, we can get the expected results to achieve the accurate assessment aim.

\section{References}

1. Li, J., Xu, X., Guo, X., Wang, L., Liu, F.: The Application Study of System Dynamics Models in Risk Assessment and Management of Equipment Acquisition. Transactions Of Beijing Institute Of Technology 26(7), 115-120 (2006)

2. Bai, K., Luo, R.: Study on risk assessment of trasmission and distribution equipments. Electric Power 42(10), 48-51 (2009)

3. Yang, G., Kang, C., Li, F., Kirschen, D.: Fiexibility and risk assessment of power grid planning schemes. Power System Protection And Control 36(23), 1-7 (2008)

4. Yu, Y.: Review of Study on Methodology of Security Regions of Power System. Journal of Tianjin University 41(6), 635-646 (2008) 